\title{
Supply Chain Financial Ecology Model Design and Risk Management Research
}

\author{
Baosen Wang, Wenjiao Lan* and Chunming Fan \\ 1st Fuhe Street, Tongzhou District, Beijing, China \\ ${ }^{*}$ Corresponding author
}

\begin{abstract}
Supply chain finance is an emerging model, which treats the core enterprises in the supply chain and the upstream and downstream SMEs as a whole. The commercial banks provide financial services to the entire supply chain. According to the natural ecosystem structure model, this paper summarized the composition of the supply chain financial ecosystem, designed the financial eco-mode of the supply chain, cleverly integrated the financial tree theory, and vividly linked the relationship among the environment, big data platform and enterprises. Through the use of VaR model for operational risk analysis and research, then used Matlab software to get VaR value. This paper used historical data to prove that banks and factoring companies and financial leasing companies strengthen cooperation to reduce operational risk, which also proved the scientific nature of supply chain financial eco-mode design.
\end{abstract}

Keywords-supply chain finance; financial ecology; operational risk; VaR model

\section{COMPOSITION OF SUPPLY CHAIN FINANCIAL ECOSYSTEM}

Supply chain financial ecology is a concept with Chinese characteristics, so a lot of foreign researches on ecology are about risk. Keynes believed that the inevitable factors that caused financial instability were the asymmetric information and irrational investment[1].Michael Lamoureux pointed out that supply chain finance should be placed on the ecosystem to get better research so that core and upstream and downstream enterprises can get optimization of capital and supply chain models[2].Parker emphasized that different functional departments in the ecosystem should work together and plan together to stabilize the development of the ecosystem[3].Russell pointed out that in order to develop a stable ecosystem and get a long-term development, a more comprehensive sales system and a corresponding operation management system should be established[4].

Supply chain financial ecosystem is a complete ecosystem, which takes into account the different industries, different regions, different companies. Different businesses, businesses and government will be linked ,to the Internet of things and the big data, cloud computing and other advanced technology. Dewei Zhu's[5] research showed the improvement of financial ecology, first, it is conducive to preventing and resolving financial risks, making its non-performing loans decline. The second is to help optimize the geographical environment and better promote the local economic development. Third, it helps to raise the awareness of honesty and risk and the awareness of risk in all walks of life and speed up the construction of a social credit system.

Supply chain financial ecology has a large number of data support, relying on the real trade and industrial chain as the background, is committed to combining production and financial[6].Good financial environment is beneficial to optimize the internal structure of commercial banks and earnings management, thereby reducing operational risk[7].Supply chain financial ecosystem consists of three parts: ecological environment, ecological interests and supply chain finance platform. Supply chain finance ecological interests, including the core business, upstream and downstream small and medium enterprises, logistics companies and financial institutions. Supply chain finance platform includes information processing platform (online, information flow), operating platform (offline, logistics), service platform (capital flow) and risk management platform. A complete integrated supply chain finance service platform integrates information flow, logistics, capital flow, business flow and risk system. In this paper, the supply chain finance integrated service platform is divided into four parts, which are supply chain financial information processing platform, supply chain financial operation platform, supply chain financial service platform, supply chain financial risk management platform[8].

\section{Supply Chain FinANCIAL ECOlOGy Model DesigN}

According to the principle of adaptability and diversity, the principle of stability and sustainable development and the principle of science in supply chain financial eco-mode design, this paper designs a mutually beneficial symbiotic supply chain financial eco-mode based on the traditional supply chain financial eco-mode. The financial eco-environment is like a tree root. The big data platform is like a trunk. Branches are used to represent different industries in different regions, commercial banks, factoring companies, financial leasing companies, core enterprises, upstream and downstream SMEs and logistics enterprises. Big data platform from the ecological environment and financial institutions to get sufficient information, funds, and then all of this information quickly and effectively passed out, companies can accept these "nutrients." Due to the effectiveness of these nutrients and the full service of big data platform, these enterprises are no longer restricted by the regions and industries. Therefore, the tree of financial ecology is the fruit of different fields, different industries and different regions, Which also reflects the characteristics of the financial ecology across industries and regions. In this model, commercial banks and factoring 
companies and financial leasing companies step up their cooperation to jointly provide financial services for the supply chain. To build a good financial environment, the government should reduce its intervention in the local economy and financial markets, improve laws and regulations so that the political, cultural, economic and legal harmonizations will develop in line with the local economic development trend. The full application of big data platform enables it to serve all aspects of the entire supply chain in all aspects and accelerate the real-time tracking and sharing of information transmission, information sharing, information exchange and logistics information.

One of the most notable features of supply chain financial eco-mode is the establishment of integrated supply chain finance service platform. It brings together the big data, information flow, capital flow, logistics, business flow and wind control management platform, a full range of control supply chain from the procurement of raw materials to the final sale of the entire process of payment, at the same time rely on Internet technology and data analysis technology, It make the formation of an interactive regulatory and risk control mechanism, information sharing and cooperation winwin situation. At the same time, the supply chain finance integrated service platform records the real data of the past SMEs in the upstream and downstream. Under the circumstance that the data supports the ecological environment, commercial banks and other financial institutions can directly fund upstream suppliers and downstream distributors. After the upstream suppliers of goods sent to the core enterprise funds received and then return to a financial institution. Similarly, downstream distributors to the flow of funds to the core business, the core business delivery to the downstream distributors, dealers will sell to consumers to get the funds received and then flow to financial institutions. That creates a closed flow of funds. On the other hand, the closed capital flow reflects that the ecological model is a self-compensating trade model, thus avoiding the risks of external use of funds, ensuring the efficient recycling of funds and ensuring the stable development of the financial eco-mode of the supply chain.

Due to the constantly changing ecological environment and the external pressure of competition, the ecosystem status will also change. Supply chain finance service platform should be updated in a timely manner to maintain data and technical personnel, along with members of the ecological body time to adjust their own evolution, feedback to the consumer. In this way, consumers' consumption behavior can positively affect the ecological environment and make its supply chain financial ecology develop towards healthy development. Positive healthy competition and ecological environment can make its financial subjects rationalize and control all kinds of costs, which is low cost and high efficiency, so as to bring a positive effect on the ecosystem and promote the evolution of the entire ecosystem, so that supply chain finance ecological model tends to be stable.

In the supply chain financial eco-mode, the establishment of big data platform has solved the problem of information asymmetry. Logistics, information flow, capital flow and past trade data for small and medium-sized enterprises will be presented in the data platform, which reduce credit risk. For their own survival and development, all enterprises have formed a reasonable division of labor and cooperation with other enterprises, forming a relationship that is interrelated, interdependent, interactive and competing with each other. Financial institutions will also make business innovations and product innovations that will make their ecological entities and their ecological environment more cohesive. The diversity of supply chain financial eco-mode also determines that its ecological main body will find its own foothold with the constant changes of ecological environment, and also makes the supply chain financial eco-mode more stable and sustainable development.

\section{THE MAIN RISKS OF SUPPLy CHAIN FINANCIAL ECO- MODE}

Supply chain financial ecology based on real transactions, with relatively good returns, but the details of the risk control is still the focus of research[9].There are many factors leading to the uncertainty of supply chain financial eco-mode, which mainly comes from the uncertainty of financial ecoenvironment. This article roughly divided the risks involved in the supply chain financial ecology into: operational risk, credit risk and market risk.

\section{A. Operational Risk}

The most important of supply chain financial eco-mode is big data platform integration, every aspect of data processing is crucial. The quality of personnel, the level of business information, the stability of the network system and the level of resource sharing among the main financial operations all directly affect the operational risk of the supply chain financial eco-mode. This article classifies operational risk into six broad categories: resource sharing, staffing, external fraud, internal fraud, business informatics and network system vulnerabilities.

\section{B. Credit Risk}

Core enterprises play a crucial role in information flow, logistics and capital flow. Once the credit problems arise in the core enterprises, it will inevitably endanger the upstream and downstream enterprises in the supply chain, affect the safety of the entire supply chain finance and also undermine the stability of the supply chain financial ecology.

In the supply chain financial eco-mode, small and mediumsized enterprises as direct lending entities, unsuitable corporate governance structure, imperfect system, non-transparent information, unstable management, anti-risk ability and other unstable factors will make the whole supply chain bear a greater credit risk.

\section{Market Risk}

The interest rate liberalization of China is not yet mature. Pricing of bank supply chain financing products still takes the fixed interest rates as the same to traditional working-capital loans. Once the interest rate changes, the bank can not adjust the interest rate in time and only can make adjustments until the beginning of the next benchmark year when the benchmark interest rate changes. This makes banks take the risks posed by 
changes in interest rates. In addition, there is a lot of business in supply chain finance that is international trade. In international trade, whether single import or export business or back-to-back letter of credit transactions, if not using the same currency will be subject to exchange rate risk. In a market economy, the volatility of commodity prices is a normal phenomenon, and there is a greater possibility of price changes in a given period of time. Therefore, there is also price risk in the supply chain finance business.

\section{VAR MEASUREMENT OF OPERATIONAL RISK IN SUPPLY CHAIN FINANCIAL ECOLOGY MODEL}

\section{A. Construction of VaR Model in Supply Chain Financial Ecology Model}

In recent years, the $\mathrm{VaR}$ model is simple and easy to operate and analyze. It is widely used in various fields such as risk analysis. Therefore, the VaR model is one of the main financial risk measurement methods. Experts and scholars have done a great deal of work to study the VaR model, but also make different out to optimize the improved model to make the result more accurate. Gaivoronski and Pflug expected to eliminate local irregularities in the model to obtain similar VaR values, thus obtaining the mean-VaR effective frontier in the study[10].Berkowtz proposed a new evaluation of $\mathrm{VaR}[11]$.Despite the high level of confidence, there is still the possibility of unpredictable loss[12].Generally speaking, there are three kinds of measurement methods of operational risk: basic index method, standard method and advanced measurement method. Advanced measurement methods include internal measurement, scorecard method and loss distribution method. In this paper, loss distribution method is used to measure the operational risk in the supply chain financial model.

\section{1) Loss distribution model}

This article draws on Philippe Jorion's method of calculating operational risk VaR in Value at Risk that the loss caused by operational risk in the supply chain financial eco-mode can be explained by two independent random variables, namely, the frequency $\mathrm{N}$ and severity of the loss $\mathrm{X}$. The frequency of loss is the number of times a certain type of supply chain financial operation risk occurs during a fixed period of time. The severity of the loss is the operational risk loss, generally measured in monetary units, such as yuan.

\section{a) The distribution of loss frequency}

Binomial distribution, geometric distribution, Poisson distribution, etc. are suitable for the frequency model. It is assumed that the loss frequency obeys the geometric distribution in this paper ,the probability density function when loss frequency is $\mathrm{n}$

$$
f(n)=P(1-P)^{n-1} \quad n=1,2, \ldots,
$$

$\mathrm{P}$ indicates the probability of a risk event occurring once,and $0<P<1, f(n)$ decrease by the geometric progression,the expected loss frequency $E(N)=1 / P$, variance $D(N)=(1-P) P^{2}$.

\section{b) Distribution of severity of loss}

Operating loss data does not obey normal distribution at almost any time. This paper assumes that the severity of the loss $\mathrm{X}$ follows an exponential distribution. The probability density function of $\mathrm{X}$ is

$$
g(x)=\lambda e^{-\lambda x} \quad x \neq 0
$$

2) Data collection and preliminary analysis of loss distribution

There are many main participants in the supply chain financial eco-mode. Based on the historical data of commercial banks, factoring companies and financial leasing companies in our country and the loss distribution of the traditional supply chain financial model, this article makes a comprehensive statistical analysis of these data and summarizes the classification of operational risk according to the financial ecomode of the supply chain, as shown in Table I ,Table II, Table III

TABLE I. DISTRIBUTION OF OPERATIONAL RISK IN CHINA'S COMMERCIAL BANKS FROM 2004 TO 2014

\begin{tabular}{|l|c|}
\hline Category & Number of samples \\
\hline Internal fraud & 15 \\
\hline External fraud & 15 \\
\hline Personnel operation & 25 \\
\hline Network system vulnerabilities & 33 \\
\hline Business information level & 30 \\
\hline Resource sharing & 10 \\
\hline
\end{tabular}

TABLE II. DISTRIBUTION OF OPERATIONAL RISK IN IMPORT FACTOR FROM 2010 TO 2014

\begin{tabular}{|l|c|}
\hline Category & Number of samples \\
\hline Internal fraud & 3 \\
\hline External fraud & 2 \\
\hline Personnel operation & 7 \\
\hline Network system vulnerabilities & 6 \\
\hline Business information level & 5 \\
\hline Resource sharing & 1 \\
\hline
\end{tabular}

TABLE III. DISTRIBUTION OF OPERATIONAL RISK IN FINANCIAL LEASING COMPANY FROM 2010 TO 2014

\begin{tabular}{|l|c|}
\hline Category & Number of samples \\
\hline Internal fraud & 1 \\
\hline External fraud & $8 \mathrm{f}$ \\
\hline Personnel operation & 5 \\
\hline Network system vulnerabilities & 5 \\
\hline Business information level & 4 \\
\hline Resource sharing & 0 \\
\hline
\end{tabular}


We can see from the above table that after the reclassification of operational risk in the supply chain financial eco-mode, there are more operational risk events caused by network system vulnerabilities and business informationalized level. This reflects the maintenance of the data platform in supply chain financial eco-mode is a key issue on the other hand.

According to the requirements of loss distribution method, this paper classifies the collected samples according to the types of loss events in the financial eco-mode of supply chain and conducts statistical analysis, as shown in Table IV

TABLE IV. DISTRIBUTION OF OPERATING RISK LOSSES IN SUPPLY CHAIN FINANCE ECOLOGY MODEL (MILLION)

\begin{tabular}{|l|c|c|c|}
\hline Category & $\begin{array}{l}\text { Commercial } \\
\text { banks }\end{array}$ & $\begin{array}{l}\text { Factoring } \\
\text { company }\end{array}$ & $\begin{array}{l}\text { financial leasing } \\
\text { company }\end{array}$ \\
\hline Stock pledge & 175 & 8 & 67 \\
\hline receivables & 56 & 40 & 6 \\
\hline Prepayments & 48 & 2 & 3 \\
\hline
\end{tabular}

It can be seen from Table 4 that stock pledge has the largest loss of operational risk. This may be because stock pledges generally pledged to the logistics company goods to achieve the transfer of possession of the material. However, because of different logistics company scales in China and no unified standard in warehousing, it is easy to make mistakes in terms of regulation, personnel operation and network system. The article will be from the stock pledge / commercial bank, inventory pledge / factoring company, inventory pledge / financing leasing company, accounts receivable / commercial bank, accounts receivable / factoring companies, accounts receivable / financing leasing company, prepayments / commercial banks, prepayments / factoring companies, prepayments / leasing companies these nine categories of operational risk have tested in the generalized Pareto distribution.

\section{B. Operational Risk Analysis in Supply Chain Financial Ecology Model}

\section{1) Empirical analysis of loss distribution}

a) Empirical analysis of inventory pledge / commercial banks case

Use SPSS software to analyze the amount of inventory pledging / commercial bank losses, sample averages $=42257.56$,standard deviation of samples $=145563.53$, Skewness $=4.34$,Kurtosis $=40.31$,Data's from the intuitive degree of dispersion is high and does not meet the normal distribution, in addition, kurtosis is larger, so the distribution has a larger fat tail phenomenon.

The generalized Pareto distribution has a thick tail characteristic. Therefore, the text assumes that the Pareto distribution follows the generalized Pareto distribution in the financial eco-supply chain model, and then tests. In this paper, Kolmogorov test for non-parametric fitting test. The likelihood function can be derived from the generalized Pareto distribution function.

$$
L(\varepsilon, \beta, y)=n \ln \varepsilon-n \ln \beta-\left(\frac{1}{\varepsilon}+1\right) \sum_{i=1}^{n} \ln \left(1+\frac{\varepsilon}{\beta} y_{i}\right)
$$

The likelihood function is used to derive the likelihood equation and using the maximum likelihood method to get the maximum likelihood estimation $\hat{\varepsilon}=481, \hat{\beta}=0.78$.

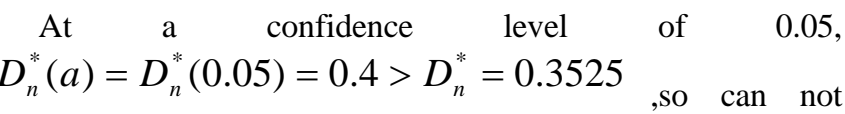
reject the null hypothesis.That is, the amount of loss of inventory pledging / business information can not be rejected subject to generalized Pareto distribution.

b) Empirical analysis of stock pledge / factoring company cases

Using the SPSS to make statistical analysis on the amount of losses of inventory pledge / factoring companies, the result is as follows sample averages $=43247.91$,standard deviation of samples=134563.53, $\quad$ Skewness $=4.56$, Kurtosis=24.84. The amount of such events does not fall within the normal distribution. Using Kolmogorov tes, at a confidence level of $0.05, D_{n}^{*}(a)=D_{n}^{*}(0.05)=0.4>D_{n}^{*}=0.2833$.Can not refuse the assumption that the amount of loss in corporate finance / infraction enforcement cases obeys the generalized Pareto distribution. Use the maximum likelihood method to estimate the parameters $\hat{\varepsilon}=459, \hat{\beta}=0.65$.

c) Empirical analysis of stock pledge / financing lease cases

Using the SPSS to make statistical analysis on the amount of losses of inventory pledge / financing leasing companies, sample averages $=42257.56$,standard deviation of samples $=145563.53$,Skewness $=4.34$,Kurtosis $=25.31$. The amount of such events does not fall within the normal distribution. Using Kolmogorov test, at a confidence level of $0.05, D_{n}^{*}(a)=D_{n}^{*}(0.05)=0.4>D_{n}^{*}=0.2901$.Therefore, we can not reject the null hypothesis that we can not refuse corporate financial / system vulnerabilities losses under the generalized Pareto distribution. Use the maximum likelihood method to estimate the parameters $\hat{\varepsilon}=501, \hat{\beta}=0.59$.

d) Empirical analysis of accounts receivable / commercial bank cases

Using the SPSS to make statistical analysis on the amount of losses of accounts receivable / commercial banks, sample averages $=412357.76$,standard deviation of samples $=137653.12$, Skewness $=4.14$,Kurtosis $=24.68$. The amount of such events does not fall within the normal distribution. Using Kolmogorov test, at a confidence level of $0.05, D_{n}^{*}(a)=D_{n}^{*}(0.05)=0.4>D_{n}^{*}=0.2793$. Therefore, we can not reject the null hypothesis that we can not refuse corporate financial / system vulnerabilities losses under the 
generalized Pareto distribution. Use the maximum likelihood method to estimate the parameters $\hat{\varepsilon}=490, \hat{\beta}=0.43$.

e) Empirical analysis of accounts receivable / factoring company cases

Using the SPSS to make statistical analysis on the amount of losses of accounts receivable / factoring companies, sample averages $=404337.12$,standard deviation of samples $=132833.09$, Skewness $=4.33$, Kurtosis $=22.98$. The amount of such events does not fall within the normal distribution. Using Kolmogorov test, at a confidence level of $0.05, D_{n}^{*}(a)=D_{n}^{*}(0.05)=0.4>D_{n}^{*}=0.2832$. Therefore, we can not reject the null hypothesis that we can not refuse corporate financial / system vulnerabilities losses under the generalized Pareto distribution. Use the maximum likelihood method to estimate the parameters $\hat{\varepsilon}=487, \hat{\beta}=0.42$.

\section{f) Empirical analysis of accounts receivable / financing} leasing companies

Using the SPSS to make statistical analysis on the amount of losses of accounts receivable / financing leasing companies, sample averages $=432661.56$,standard deviation of samples $=134522.54, \quad$ Skewness $=4.26$, Kurtosis $=21.99$. The amount of such events does not fall within the normal distribution. Using Kolmogorov test, at a confidence level of $0.05, D_{n}^{*}(a)=D_{n}^{*}(0.05)=0.4>D_{n}^{*}=0.2901$. Therefore, we can not reject the null hypothesis that we can not refuse corporate financial / system vulnerabilities losses under the generalized Pareto distribution. Use the maximum likelihood method to estimate the parameters $\hat{\varepsilon}=472, \hat{\beta}=0.41$.

g) Empirical analysis of prepayments / commercial banks cases

Using the SPSS to make statistical analysis on the amount of losses of prepayments / commercial banks, sample averages $=409876.12$,standard deviation of samples $=136594.12$, Skewness $=4.19$, Kurtosis $=23.91$. The amount of such events does not fall within the normal distribution. Using Kolmogorov test, at a confidence level of $0.05, D_{n}^{*}(a)=D_{n}^{*}(0.05)=0.4>D_{n}^{*}=0.2787$.Therefor e, we can not reject the null hypothesis that we can not refuse corporate financial / system vulnerabilities losses under the generalized Pareto distribution. Use the maximum likelihood method to estimate the parameters $\hat{\varepsilon}=484, \hat{\beta}=0.44$.

h) Empirical analysis of prepayments / factoring company cases

Using the SPSS to make statistical analysis on the amount of losses of prepayments / factoring companies, sample averages $=412300.67$,standard deviation of samples $=137620.23$, Skewness $=4.08$, Kurtosis $=22.99$. The amount of such events does not fall within the normal distribution. Using Kolmogorov test, at a confidence level of $0.05, D_{n}^{*}(a)=D_{n}^{*}(0.05)=0.4>D_{n}^{*}=0.2692$.Therefore, we can not reject the null hypothesis that we can not refuse corporate financial / system vulnerabilities losses under the generalized Pareto distribution. Use the maximum likelihood method to estimate the parameters $\hat{\varepsilon}=472, \hat{\beta}=0.40$.

\section{i) Empirical analysis of prepayments / financing Leasing} company cases

Using the SPSS to make statistical analysis on the amount of losses of prepayments / financing leasing companies, sample averages $=419862.31$,standard deviation of samples $=136281.68$, Skewness $=4.11$, Kurtosis $=23.19$. The amount of such events does not fall within the normal distribution. Using Kolmogorov test, at a confidence level of $0.05, D_{n}^{*}(a)=D_{n}^{*}(0.05)=0.4>D_{n}^{*}=0.2693$. Therefore, we can not reject the null hypothesis that we can not refuse corporate financial / system vulnerabilities losses under the generalized Pareto distribution. Use the maximum likelihood method to estimate the parameters $\hat{\varepsilon}=474, \hat{\beta}=0.41$.

As can be seen from the above results, stock pledge / commercial bank, inventory pledge / factoring company, inventory pledge / finance lease company, accounts receivable / commercial bank, accounts receivable / factoring company, accounts receivable / finance leasing company, prepayments / commercial banks, prepay accounts / factoring companies, prepayments / finance leasing companies all follow the generalized Pareto distribution. The above empirical results have two aspects of the policy implications: 1.In the supply chain financial eco-mode, the loss distribution method is more accurate than other methods of operational risk measurement. 2.When applying the loss distribution method, it is possible that most subclasses satisfy the generalized Pareto distribution and some subclasses conform to other distributions, such as Weibull distribution, normal distribution, etc. Although the empirical results in this paper are shown to be subject to the generalized Pareto distribution, it can not be ruled out that there may exist other generalized Pareto distributions in other subclasses. Then this time need to make the calculate separately and then add up. Based on the above generalized Pareto distributions, the operational risk capital is calculated using the loss distribution method.

\section{2) Calculate operational risk capital}

Before calculating the capital, we analyze the loss frequency data of commercial banks, factoring companies and financial leasing companies first, as shown in the following table V, VI, VII

TABLE V. ANALYSIS ON THE LOSS FREQUENCY DATA OF CHINESE COMMERCIAL BANKS

\begin{tabular}{|l|l|l|l|}
\hline average value & 17.01 & kurtosis & 0.40 \\
\hline median & 13.00 & skewness & 1.01 \\
\hline mode & 9.00 & minimum & 3.00 \\
\hline $\begin{array}{l}\text { Standard } \\
\text { deviation }\end{array}$ & 11.12 & maximum & 33.00 \\
\hline variance & 126.21 & summation & 355.00 \\
\hline
\end{tabular}


TABLE VI. ANALYSIS ON THE LOSS FREQUENCY DATA OF CHINESE IMPORT FACTOR

\begin{tabular}{|l|l|l|l|}
\hline average value & 12.34 & kurtosis & 0.30 \\
\hline median & 9.00 & skewness & 0.91 \\
\hline mode & 6.00 & minimum & 2.00 \\
\hline $\begin{array}{l}\text { standard } \\
\text { deviation }\end{array}$ & 8.05 & maximum & 21.00 \\
\hline variance & 98.76 & summation & 201.00 \\
\hline
\end{tabular}

TABLE VII. ANALYSIS ON THE LOSS FREQUENCY DATA OF FINANCIAL LEASING COMPANY

\begin{tabular}{|l|l|l|l|}
\hline average value & 11.34 & kurtosis & 0.30 \\
\hline median & 7.00 & skewness & 0.87 \\
\hline mode & 5.00 & minimum & 2.00 \\
\hline standard deviation & $\mathbf{8 . 0 5}$ & maximum & 19.00 \\
\hline variance & 96.14 & summation & 196.00 \\
\hline
\end{tabular}

The article used matlab software to fit the collected loss frequency data, the results shown in Table VIII. The negative binomial distribution and the geometric distribution can fit the data better from the table.

TABLE VIII. FITTING RESULTS OF LOSS FREQUENCY DISTRIBUTION OF OPERATIONAL RISK

\begin{tabular}{|l|c|c|}
\hline \multicolumn{1}{|c|}{ frequency distribution } & Chi-square & P \\
\hline Negative binomial distribution & 1.98 & 0.161 \\
\hline Geometric distribution & 3.58 & 0.060 \\
\hline Poisson distribution & 8.72 & 0.003 \\
\hline Binomial distribution & 9.92 & 0.000 \\
\hline
\end{tabular}

The above has given the loss distribution model and the loss frequency, the following apply the Matlab software to Monte Carlo simulation to get VaR value. Confidence level is $95 \%$.

TABLE IX. THE SUMMARY OF OPERATIONAL RISK CAPITAL

\begin{tabular}{|l|c|c|c|}
\hline & $\begin{array}{c}\text { Comme } \\
\text { rcial Bank }\end{array}$ & $\begin{array}{c}\text { Factoring } \\
\text { Company }\end{array}$ & $\begin{array}{r}\text { Finan } \\
\text { ce Leasing } \\
\text { Company }\end{array}$ \\
\hline $\begin{array}{l}\text { 95\% confidence } \\
\text { level operating risk } \\
\text { VaR (yuan) }\end{array}$ & $8.76 \times 10^{7}$ & $0.73 \times 10^{7}$ & $0.69 \times 10$ \\
\hline
\end{tabular}

\section{Result analysis}

From the above operation results we can see, in supply chain financial eco-mode, whether it is commercial banks, factoring companies or financial leasing companies, there are operational risks in inventory pledge, accounts receivable and prepayments which all subject to generalized Pareto distribution. Operating risk capital calculated by loss distribution method. At the confidence level of 95\%, the VaR values of commercial banks, factoring companies and finance leasing companies are quite different. The VaR of commercial banks is the largest, and the $\mathrm{VaR}$ of finance leasing companies is the smallest. It suggests that financial leasing companies have relatively good operational risk management. The combination of commercial banks and factoring companies and the combination of commercial banks and financial leasing companies can reduce the reserved capital of commercial banks and at the same time reduce the operational risks of the supply chain financial eco-mode.

In addition, good financial environment can make the financial internal and external operating mechanism more efficient, and can maximize the interests of financial institutions, thereby helping to improve the quality of earnings, inhibit the loss of operational losses, thereby reducing the reserve capital and reduce the operation risk.

The construction of big data platform in supply chain financial eco-mode and the multi-faceted participation and data application of supply chain financial eco-service platform can also effectively restrain the internal fraud, external fraud and personnel operations in the traditional supply chain financial model Problems, thereby reducing the operational risk.

\section{CONCLUSION}

This article designed the supply chain financial eco-mode, in which the main is interdependent and mutually beneficial. These companies constitute the value chain or value network business ecosystem. Compared with the traditional model, all the subjects in the supply chain financial eco-system have a higher degree of cohesion and a more stable and sustainable development.

The article used the VaR model to analyze the operation risk and used the generalized Pareto distribution to test the data. Then using the loss distribution method to calculate the VaR of operational risk, the result is that the VaR of commercial bank is the largest and the VaR of finance leasing company is the smallest. The final result showed that commercial banks provide financial services to upstream and downstream enterprises need larger amounts of capital, whereas factoring companies and financial leasing companies have a much smaller VaR. Therefore, this paper suggests that banks should strengthen cooperation with factoring companies and financial leasing companies to reduce operational risk. Finally, the article also analyzed that the financial eco-environment and big data platform can effectively reduce operational risk. The research of supply chain finance in our country can be considered from the ecological point of view. The supply chain finance ecological mode that the article designed and the operation risk research hope can provide the reference for the future research.

\section{REFERENCES}

[1] Keynes. Enterprise systems and the supply chain[J]. Journal of Enterprise Information Management,2005,17(1):44 46

[2] Michael Lamoureux. A supply chain finance prime[J]. Supply Chain Finance, 2007, (5): 34 48

[3] C. Parker,N.S. Hawkins.Sharing of Information Across Studies to Inform Choice of Functional Form When Conducting Parametric Survival Analysis[J] . Value in Health . 2014 (7)

[4] Russell Davis. Heart failure: key points and recent developments in management[J] . Prescriber . 2015 (6)

[5] Dewei Zhu. Optimize Financial Structure: Another Perspective to Improve Financial Ecology[J].Shanghai Finance,2006,(01):19-23. 
[6] Xiangjun He,Ding Zhou. Innovative Exploration of the Operation Mode of Supply Chain Finance Business[J].Manufacturing automation,2012,(34):72 81

[7] Ming Zhang,Lu Xie,Lijun Ma.Financial Ecology Environment and Earnings Quality of Commercial Banks[J].Finance Research,2015,(05):117 131

[8] Xuefeng Xu,Jianxin Xia. Some Problems in Innovative Development of Supply Chain Finance in China[J].Shanghai Finance,2014,(3):23 26

[9] Xinyu Huang.Supply Chain Finance New Ecological Picture[J].CFO,2016,(16):32 43

[10] Lingyun Tang.Research on Supply Chain Financial Operational Risk Measurement Based on VaR[J].Chinese Market,2010,(15):12 14

[11] Berkowtz. Kalman Filter or VAR Models to Predict Unemployment Rate in Romania[J].Computational and Mathematical Methods in Medicine, 2015, (6): 64 72

[12] ]Danielsson. Examining Eurozone Crisis and Unemployment Relationship Using Var Models[J].Supply Chain Finance, 2016, (2): 34 48 